\title{
On Fuzzy $\gamma$ - Semi Open Sets and Fuzzy $\gamma$ - Semi Closed Sets in Fuzzy Topological Spaces
}

\author{
R.Usha Parameswari ${ }^{1}$, K.Bageerathi ${ }^{2}$, \\ ${ }^{1,2}$ Department of Mathematics, Govindammal Aditanar College for Women, Tiruchendur-628215, India.
}

\begin{abstract}
The aim of this paper is to introduce the concept of fuzzy $\gamma$ - semi open and fuzzy $\gamma$ - semi closed sets of a fuzzy topological space. Some characterizations are discussed, examples are given and properties are established. Also, we define fuzzy $\gamma$ - semi interior and fuzzy $\gamma$ - semi closure operators. And we introduce fuzzy $\gamma$ - $t$-set, $\gamma$-SO extremely disconnected space analyse the relations between them.
\end{abstract} MSC 2010: 54A40, $03 E 72$.

Key words: Fuzzy $\gamma$-open, fuzzy $\gamma$ - closed, fuzzy $\gamma$ - semi open, fuzzy $\gamma$ - semi closed, fuzzy $\gamma$ - semi interior and fuzzy $\gamma$ - semi closure, $\gamma$ - $t$-set and fuzzy topology.

\section{Introduction}

The concepts of fuzzy sets and fuzzy set operations were first introduced by L.A.Zadeh [6] in his paper. Let $X$ be a non empty set and I be the unit interval [0,1]. A Fuzzy set in X is a mapping from X in to I. In 1968, Chang [3] introduced the concept of fuzzy topological space which is a natural generalization of topological spaces. Our notation and terminology follow that of Chang. Azad introduced the notions of fuzzy semi open and fuzzy semi closed sets. And T.Noiri and O.R.Sayed[5] introduced the notion of $\gamma$-open sets and $\gamma$-closed sets. Swidi Oon[4] studied some of its properties.

Through this paper $(\mathrm{X}, \tau)$ (or simply $\mathrm{X}$ ), denote fuzzy topological spaces. For a fuzzy set $\mathrm{A}$ in a fuzzy topological space $\mathrm{X}, \operatorname{cl}(\mathrm{A}), \operatorname{int}(\mathrm{A}), \mathrm{A}^{\mathrm{C}}$ denote the closure, interior, complement of A respectively. By $0_{\mathrm{x}}$ and $\mathrm{I}_{\mathrm{x}}$ we mean the constant fuzzy sets taking on the values 0 and 1 , respectively.

In this paper we introduce fuzzy $\gamma$-semi open sets and fuzzy $\gamma$-semi closed sets its properties are established in fuzzy topological spaces. The concepts that are needed in this paper are discussed in the second section. The concepts of fuzzy $\gamma$-semi open and fuzzy $\gamma$-semi closed sets in fuzzy topological spaces and studied their properties in the third and fourth section respectively. Using the fuzzy $\gamma$ - semi open sets, we introduce the concept of fuzzy $\gamma$-SO extremely disconnected space. The section 5 and 6 are dealt with the concepts of fuzzy $\gamma$-semi interior and $\gamma$-semi closure operators. In the last section, we define fuzzy $\gamma$-t-sets and discuss the relations between this set and the sets defined previously.

\section{Preliminaries}

In this section, we give some basic notions and results that are used in the sequel.

Definition 2.1: A fuzzy set A of a fuzzy topological space $\mathrm{X}$ is called:

1) fuzzy semi open (semi closed) [2] if there exists a fuzzy open (closed) set $\mathrm{U}$ of $\mathrm{x}$ such that $\mathrm{U} \leq \mathrm{A} \leq \mathrm{cl} \mathrm{U}$ ( int $\mathrm{U} \leq \mathrm{A} \leq \mathrm{U}$ ).

2) fuzzy strongly semi open (strongly semi closed) [4] if $\mathrm{A} \leq \operatorname{int}(\mathrm{cl}($ int $\mathrm{A})$ )

$(\mathrm{A} \geq \operatorname{cl}(\operatorname{int}(\mathrm{cl} A)))$.

3) fuzzy $\gamma$-open (fuzzy $\gamma$-closed) [5] if $\mathrm{A} \leq(\operatorname{int}(\operatorname{cl} \mathrm{A})) \vee \operatorname{cl}(\operatorname{int}(\mathrm{A}))$

$(\mathrm{A} \geq(\operatorname{cl}(\operatorname{int}(\mathrm{A}))) \wedge(\operatorname{int}(\mathrm{cl}(\mathrm{A}))))$.

Definition 2.2[7]: If $\lambda$ is a fuzzy set of $X$ and $\mu$ is a fuzzy set of $Y$, then

$(\lambda \times \mu)(\mathrm{x}, \mathrm{y})=\min \{\lambda(\mathrm{x}), \mu(\mathrm{y})\}$, for each $\mathrm{X} \times \mathrm{Y}$.

Definition 2.3[2]: An fuzzy topological space $\left(X, \tau_{1}\right)$ is a product related to an fuzzy topological space $\left(Y, \tau_{2}\right)$ if for fuzzy sets $\mathrm{A}$ of $\mathrm{X}$ and $\mathrm{B}$ of $\mathrm{Y}$ whenever $\mathrm{C}^{\mathrm{c}} \geq \mathrm{A}$ and $\mathrm{D}^{\mathrm{c}} \geq \mathrm{B}$ implies $\mathrm{C}^{\mathrm{c}} \times 1 \vee 1 \times \mathrm{D}^{\mathrm{c}} \geq \mathrm{A} \times \mathrm{B}$, where $\mathrm{C}$ $\in \tau_{1}$ and $\mathrm{D} \in \tau_{2}$, there exist $\mathrm{C}_{1} \in \tau_{1}$ and $\mathrm{D}_{1} \in \tau_{2}$ such that $\mathrm{C}_{1}{ }^{\mathrm{c}} \geq \mathrm{A}$ or $\mathrm{D}_{1}{ }^{\mathrm{c}} \geq \mathrm{B}$ and $\mathrm{C}_{1}{ }^{\mathrm{c}} \times 1 \vee 1 \times \mathrm{D}_{1}{ }^{\mathrm{c}}=\mathrm{C}^{\mathrm{c}} \times 1 \vee 1$ $\times \mathrm{D}^{\mathrm{c}}$.

Lemma 2.4 [2]: Let $X$ and $Y$ be fuzzy topological spaces such that $X$ is product related to $Y$. Then for fuzzy sets $\mathrm{A}$ of $\mathrm{X}$ and $\mathrm{B}$ of $\mathrm{Y}$,

1) $\quad \mathrm{cl}(\mathrm{A} \times \mathrm{B})=\mathrm{cl}(\mathrm{A}) \times \mathrm{cl}(\mathrm{B})$

2) $\operatorname{int}(\mathrm{A} \times \mathrm{B})=\operatorname{int}(\mathrm{A}) \times \operatorname{int}(\mathrm{B})$

Lemma 2.5[1]: For fuzzy sets $\lambda, \mu, v$ and $\omega$ in a set $S$, one has

$(\lambda \wedge \mu) \times(v \wedge \omega)=(\lambda \times \omega) \wedge(\mu \times v)$ 


\section{Remark 2.6[5]:}

1. Any union of fuzzy $\gamma$-open sets in a fuzzy topological space $X$ is a fuzzy $\gamma$-open set.

2. Any intersection of fuzzy $\gamma$-closed sets is fuzzy $\gamma$-closed set.

3. Let $\left\{\mathrm{A}_{\alpha}\right\}_{\alpha \in \Delta}$ be a collection of fuzzy $\gamma$-open sets in a fuzzy topological space X. Then $\underset{\alpha \in \Delta}{\vee} \mathrm{A}_{\alpha}$ is fuzzy $\gamma$-open.

Definition 2.7[5]: Let A be any fuzzy set in the fuzzy topological space $X$. Then we define $\gamma$-cl $(A)=\wedge\{B: B \geq$ $\mathrm{A}, \mathrm{B}$ is fuzzy $\gamma$-closed $\}$ and

$\gamma$-int $(\mathrm{A})=\vee\{\mathrm{B}: \mathrm{B} \leq \mathrm{A}, \mathrm{B}$ is fuzzy $\gamma$-open in $\mathrm{X}\}$.

Properties 2.8[5]: Let A be any fuzzy set in the fuzzy topological space X. Then

a) $\gamma$-cl $\left(\mathrm{A}^{\mathrm{c}}\right)=(\gamma \text {-int }(\mathrm{A}))^{\mathrm{c}}$

b) $\gamma$-int $\left(\mathrm{A}^{\mathrm{c}}\right)=(\gamma-\mathrm{cl}(\mathrm{A}))^{\mathrm{c}}$

Properties 2.9[5]: Let $A$ and $B$ be any two fuzzy sets in a fuzzy topological space $X$. Then

1) $\gamma$-int $(0)=0, \gamma$-int $(1)=1$.

2) $\gamma$-int $(\mathrm{A})$ is fuzzy $\gamma$-open in $X$.

3) $\gamma$-int $(\gamma$-int $(\mathrm{A}))=\gamma$-int $(\mathrm{A})$.

4) if $\mathrm{A} \leq \mathrm{B}$ then $\gamma$-int $(\mathrm{A}) \leq \gamma$-int $(\mathrm{B})$.

5) $\gamma$-int $(\mathrm{A} \wedge \mathrm{B})=\gamma$-int $(\mathrm{A}) \wedge \gamma$-int $(\mathrm{B})$.

6) $\gamma$-int $(\mathrm{A} \vee \mathrm{B}) \geq \gamma$-int $(\mathrm{A}) \vee \gamma$-int $(\mathrm{B})$

Properties 2.10[5]: Let A and B be any two fuzzy sets in a fuzzy topological space X. Then

1) $\gamma-\operatorname{cl}(0)=0, \gamma-\operatorname{cl}(1)=1$.

2) $\gamma$-cl(A) is fuzzy $\gamma$-closed in $X$.

3) $\gamma-\operatorname{cl}(\gamma-\operatorname{cl}(\mathrm{A}))=\gamma-\operatorname{cl}(\mathrm{A})$.

4) if $\mathrm{A} \leq \mathrm{B}$ then $\gamma-\mathrm{cl}(\mathrm{A}) \leq \gamma-\operatorname{cl}(\mathrm{B})$.

5) $\gamma-\operatorname{cl}(\mathrm{A} \vee \mathrm{B})=\gamma-\operatorname{cl}(\mathrm{A}) \vee \gamma-\operatorname{cl}(\mathrm{B})$.

6) $\gamma-\mathrm{cl}(\mathrm{A} \wedge \mathrm{B}) \leq \gamma-\mathrm{cl}(\mathrm{A}) \wedge \gamma-\operatorname{cl}(\mathrm{B})$.

\section{Fuzzy $\gamma$-Semi Open Sets}

In this section we introduce the concept of fuzzy $\gamma$-semi open sets in a fuzzy topological space.

Definition 3.1: Let A be a fuzzy subset of a fuzzy topological space $(X, \tau)$. Then A is called fuzzy $\gamma$-semi open set of $\mathrm{X}$ if there exist a fuzzy $\gamma$-open set $\gamma-\mathrm{O}$ such that $\gamma-\mathrm{O} \leq \mathrm{A} \leq \mathrm{cl}(\gamma-\mathrm{O})$.

Theorem 3.2: Let $(X, \tau)$ be a fuzzy topological space. Let $A$ and $B$ be any two fuzzy subsets of $X$ and $\gamma$-int $(A) \leq$ $\mathrm{B} \leq \gamma$-cl (A). If A is a fuzzy $\gamma$-semi open set then so is B.

Proof:

Let $A$ and $B$ be a fuzzy subsets of $X$ and $\gamma$-int $(A) \leq B \leq \gamma$-cl(A). Let A be fuzzy $\gamma$-semi open set. By Definition 3.1, there exists a fuzzy $\gamma$-open set $\gamma$-O such that $\gamma-\mathrm{O} \leq \mathrm{A} \leq \mathrm{cl}(\gamma-\mathrm{O})$, it follows that $\gamma$-O $\leq \gamma$-int $(\mathrm{A}) \leq$ $\mathrm{A} \leq \gamma-\mathrm{cl}(\mathrm{A}) \leq \mathrm{cl}(\gamma-\mathrm{O})$ and hence $\gamma-\mathrm{O} \leq \mathrm{B} \leq \mathrm{cl}(\gamma-\mathrm{O})$. Thus $\mathrm{B}$ is a fuzzy $\gamma$-semi open set.

Theorem 3.3: Let $(X, \tau)$ be a fuzzy topological space. Then a fuzzy subset A of a fuzzy topological space $(X, \tau)$ is fuzzy $\gamma$-semi open if and only if $\mathrm{A} \leq \mathrm{cl}(\gamma$-int $(\mathrm{A}))$.

Proof:

Let $\mathrm{A} \leq \mathrm{cl}(\gamma$-int $(\mathrm{A}))$. Then for $\gamma$-O $=\gamma$-int(A), we have $\gamma$-int(A) $\leq \mathrm{A}$. Therefore $\gamma$-int $(\mathrm{A}) \leq \mathrm{A} \leq \mathrm{cl}(\gamma$ $\operatorname{int}(\mathrm{A}))$. Conversely, let A be a fuzzy $\gamma$-semi open. By Definition 3.1, there exists a fuzzy $\gamma$-open set $\gamma$-O such that $\gamma-\mathrm{O} \leq \mathrm{A} \leq \mathrm{cl}(\gamma-\mathrm{O})$. But $\gamma$-O $\leq \gamma$-int $(\mathrm{A})$. Thus $\mathrm{cl}(\gamma-\mathrm{O}) \leq \mathrm{cl}(\gamma$-int $(\mathrm{A}))$. Hence $\mathrm{A} \leq \operatorname{cl}(\gamma-\mathrm{O}) \leq \operatorname{cl}(\gamma$-int $(\mathrm{A}))$.

Remarks 3.4: It is obvious that every fuzzy $\gamma$-open is fuzzy $\gamma$-semi open and every fuzzy open set is fuzzy $\gamma$ semi open but the separate converses may not be true as shown by the following example.

Example 3.5: Let $X=\{a, b, c\}$ and $\tau=\left\{0,1,\left\{a_{.2}, b_{.3}, c_{.5}\right\},\left\{a_{.4}, b_{.7}, c_{.3}\right\}, \quad\left\{a_{.2}, b_{.3}, c_{.3}\right\},\left\{a_{.4}, b_{\cdot 7}, c_{.5}\right\}\right\}$. Then $(X$, $\tau)$ is a fuzzy topological space. The family of all fuzzy closed sets of $\tau$ is $\quad \tau^{c}=\{0,1,\{a .8, b .7, c .5\}$, $\left.\left\{a_{.6}, b_{.3}, c_{.7}\right\},\left\{a_{.8}, b_{.7}, c_{.7}\right\},\left\{a_{.6}, b_{.3}, c_{.5}\right\}\right\}$. Let $A=\left\{a_{.4}, b_{.6}, c_{.6}\right\}$. Then $\operatorname{cl}(\operatorname{int}(A))=\left\{a_{.6}, b_{.3}, c_{.5}\right\}$ and $\operatorname{int}(\operatorname{cl}(A))=$ $\left\{a_{.4}, b_{.7}, c_{.5}\right\}$.Therefore $\operatorname{int}(\operatorname{cl}(A)) \vee \operatorname{cl}(\operatorname{int}(A))=\left\{a_{.6}, b_{.7}, c_{.5}\right\}$. By Definition 2.1(3), A is not fuzzy $\gamma-$ open. Now let $\gamma$-int $(A)=\left\{a_{.2}, b_{.6}, c_{.6}\right\}$. Then $\quad A \leq \operatorname{cl}(\gamma$-int $(A))=\left\{a .8, b_{.7}, c_{.7}\right\}$. Thus $A$ is fuzzy $\gamma$-semi open. Example 3.6:

The next example shows that every fuzzy $\gamma$-semi open set need not be fuzzy open.

Let $X=\{a, b, c\}$ and $\tau=\left\{0,1,\left\{a_{1}, b_{.2}, c_{.3}\right\},\left\{a_{.5}, b_{.1}, c_{.4}\right\}, \quad\left\{a_{.1}, b_{.1}, c_{.3}\right\},\left\{a_{.5}, b_{.2}, c_{.4}\right\}\right\}$. Then $(X, \tau)$ is a fuzzy topological space. The family of all fuzzy closed sets of $\tau$ is $\tau^{c}=\left\{0,1,\left\{a_{.9}, b_{.8}, c_{.7}\right\},\left\{a_{.5}, b_{\cdot 1}, c_{.6}\right\},\{a .9\right.$, 
b.9, c. $\left.\left.{ }^{7}\right\},\left\{a .5, b_{.8}, c_{.6}\right\}\right\}$. Let $A=\left\{a .5, b_{3}, c_{5}\right\}$. Then $\gamma$-int(A) $=\left\{a_{.5}, b_{.3}, c_{.4}\right\}$ and $\operatorname{cl}(\gamma-\operatorname{int}(A))=\left\{a .5, b_{8}, c_{.6}\right\}$. It shows that $\mathrm{A} \leq \mathrm{cl}(\gamma$-int (A)). By using Theorem 3.3, A is fuzzy $\gamma$-semi open. But A is not a fuzzy open set.

It is clear that every fuzzy semi open is fuzzy $\gamma$-semi open but the converse need not be true as shown by the following example.

Example 3.7: Let $X=\{a, b\}$ and $\tau=\left\{0,1,\left\{a_{\cdot 2}, b_{.3}\right\}\right\}$. Then $(X, \tau)$ is a fuzzy topological space. The family of

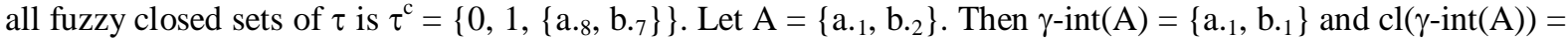
$\left\{a_{8}, b_{.7}\right\}$. It shows that $A \leq \operatorname{cl}(\gamma$-int (A)). By using Theorem 3.3, A is fuzzy $\gamma$-semi open. Now $\operatorname{cl}(\operatorname{int}(A))=\{0\}$. That shows A $\Varangle \mathrm{cl}$ (int (A)) . Hence A is not a fuzzy semi open set.

Proposition 3.8: Let $(X, \tau)$ be a fuzzy topological space. Then the union of any two fuzzy $\gamma$-semi open sets is a fuzzy $\gamma$-semi open set.

Proof:

Let $A_{1}$ and $A_{2}$ be the two fuzzy $\gamma$-semi open sets. By Theorem 3.3, $A_{1} \leq \mathrm{cl}\left(\gamma\right.$-int $\left.\left(A_{1}\right)\right)$ and $A_{2} \leq \operatorname{cl}(\gamma-$ int $\left.\left(A_{2}\right)\right)$. Therefore $A_{1} \vee A_{2} \leq \operatorname{cl}\left(\gamma\right.$-int $\left.\left(A_{1}\right)\right) \vee \operatorname{cl}\left(\gamma\right.$-int $\left.\left(A_{2}\right)\right)=\operatorname{cl}\left(\gamma\right.$-int $\left(A_{1}\right) \vee \quad \gamma$-int $\left.\left(A_{2}\right)\right)$. By using Properties 2.9(6), $A_{1} \vee A_{2} \leq \operatorname{cl}\left(\gamma\right.$-int $\left.\left(A_{1} \vee A_{2}\right)\right)$. Hence $A_{1} \vee A_{2}$ is fuzzy $\gamma$-semi open.

The following example shows that the intersection of any two fuzzy $\gamma$-semi open sets need not be fuzzy $\gamma$ semi open set.

Example 3.9: Let $X=\{a, b\}$ and $\tau=\left\{0,1,\left\{a_{.2}, b_{.4}\right\},\left\{a_{.}, b_{.5}\right\}\right\}$. Then $(X, \tau)$ be a fuzzy topological space. The family of all fuzzy closed sets of $\tau$ is $\tau^{c}=\left\{0,1,\left\{a_{8}, b_{.6}\right\},\left\{a_{.7}, b_{.5}\right\}\right\} . \quad$ Let $A=\left\{a_{.8}, b_{.9}\right\}$ and $\gamma$-int $(A)=\left\{a_{8}\right.$, b. 8$\}$. Then we get $\operatorname{cl}(\gamma$-int $(A))=\{1\}$.Thus by Theorem 3.3, A is fuzzy $\gamma$-semi open.

Let $B=\{a .9, b .7\}$. Then $\gamma$-int $(B)=\{a .9, b .5\}$ and we get $\operatorname{cl}(\gamma$-int $(B))=\{1\}$. Thus by Theorem 3.3, B is fuzzy $\gamma$ semi open. Now $A \wedge B=\left\{a_{8}, b_{.7}\right\}$ and $\gamma$-int $(A \wedge B)=\left\{a_{.6}, b_{.5}\right\}$. Then $\operatorname{cl}(\gamma$-int $(A \wedge B))=\left\{a_{.7}, b_{.5}\right\}$. Thus $A \wedge B$ is not less than or equal to $\operatorname{cl}(\gamma$-int $(A \wedge B))$. Therefore $A \wedge B$ is not fuzzy $\gamma$-semi open.

Theorem 3.10: Let $(X, \tau)$ be a fuzzy topological space and let $\left\{\mathrm{A}_{\alpha}\right\}_{\alpha \in \Delta}$ be a collection of fuzzy $\gamma$-semi open sets in a fuzzy topological space $X$. Then $\underset{\alpha \in \Delta}{\vee} A_{\alpha}$ is fuzzy $\gamma$-semi open.

Proof:

Let $\Delta$ be a collection of fuzzy $\gamma$-semi open sets of a fuzzy topological space $(X, \tau)$. Then by using Theorem 3.3, for each $\alpha \in \Delta, \mathrm{A}_{\alpha} \leq \operatorname{cl}\left(\gamma-\operatorname{int}\left(\mathrm{A}_{\alpha}\right)\right)$. Thus $\underset{\alpha \in \Delta}{\vee} \mathrm{A}_{\alpha} \leq \underset{\alpha \in \Delta}{\vee} \operatorname{cl}\left(\gamma\right.$-int $\left.\left(\mathrm{A}_{\alpha}\right)\right)$. Since $\vee \operatorname{cl}\left(\mathrm{A}_{\alpha}\right) \leq \mathrm{cl}\left(\vee \mathrm{A}_{\alpha}\right)$, $\underset{\alpha \in \Delta}{\vee} \mathrm{A}_{\alpha} \leq \operatorname{cl}\left(\underset{\alpha \in \Delta}{\vee}\left(\gamma\right.\right.$-int $\left.\left(\mathrm{A}_{\alpha}\right)\right)$. By using Remark 2.6(3), $\underset{\alpha \in \Delta}{\vee} \mathrm{A}_{\alpha} \leq \operatorname{cl}\left(\gamma\right.$-int $\left.\left(\underset{\alpha \in \Delta}{\vee} \mathrm{A}_{\alpha}\right)\right)$. Thus the arbitrary union of fuzzy $\gamma$-semi open sets is fuzzy $\gamma$-semi open.

Theorem 3.11: Let $(X, \tau)$ and $(Y, \sigma)$ be any two fuzzy topological spaces such that $X$ is product related to $Y$. Then the product $A_{1} \times A_{2}$ of fuzzy $\gamma$-open set $A_{1}$ of $X$ and a fuzzy $\gamma$-open set $A_{2}$ of $Y$ is fuzzy $\gamma$-open set of the fuzzy product space $\mathrm{X} \times \mathrm{Y}$.

Proof:

Let $A_{1}$ be a fuzzy $\gamma$-open subset of $X$ and $A_{2}$ be a fuzzy $\gamma$-open subset of $Y$. Then by Definition 2.1(3), we have $A_{1} \leq \operatorname{int}\left(\operatorname{cl}\left(A_{1}\right)\right) \vee \operatorname{cl}\left(\operatorname{int}\left(A_{1}\right)\right)$ and

$\mathrm{A}_{2} \leq \operatorname{int}\left(\operatorname{cl}\left(\mathrm{A}_{2}\right)\right) \vee \operatorname{cl}\left(\operatorname{int}\left(\mathrm{A}_{2}\right)\right)$. Now $\mathrm{A}_{1} \times \mathrm{A}_{2} \leq\left(\operatorname{int}\left(\left(\mathrm{cl}\left(\mathrm{A}_{1}\right)\right) \vee \operatorname{cl}\left(\operatorname{int}\left(\mathrm{A}_{1}\right)\right)\right) \times\left(\operatorname{int}\left(\operatorname{cl}\left(\mathrm{A}_{2}\right)\right) \vee \operatorname{cl}\left(\operatorname{int}\left(\mathrm{A}_{2}\right)\right)\right)\right.$. By using Definition 2.2,

$$
\begin{aligned}
\mathrm{A}_{1} \times \mathrm{A}_{2} & \leq \min \left\{\left(\operatorname{int}\left(\mathrm{cl}\left(\mathrm{A}_{1}\right)\right) \vee \operatorname{cl}\left(\operatorname{int}\left(\mathrm{A}_{1}\right)\right)\right),\left(\operatorname{int}\left(\operatorname{cl}\left(\mathrm{A}_{2}\right)\right) \vee \operatorname{cl}\left(\operatorname{int}\left(\mathrm{A}_{2}\right)\right)\right)\right\} \\
& =\left(\operatorname{int}\left(\operatorname{cl}\left(\mathrm{A}_{1}\right)\right) \vee \operatorname{cl}\left(\operatorname{int}\left(\mathrm{A}_{1}\right)\right)\right) \wedge\left(\operatorname{int}\left(\operatorname{cl}\left(\mathrm{A}_{2}\right)\right) \vee \operatorname{cl}\left(\operatorname{int}\left(\mathrm{A}_{2}\right)\right)\right) \\
& =\left(\operatorname{int}\left(\mathrm{cl}\left(\mathrm{A}_{1}\right)\right) \wedge \operatorname{int}\left(\operatorname{cl}\left(\mathrm{A}_{2}\right)\right) \vee\left(\operatorname{cl}\left(\operatorname{int}\left(\mathrm{A}_{1}\right)\right) \wedge \operatorname{cl}\left(\operatorname{int}\left(\mathrm{A}_{2}\right)\right)\right)\right. \\
& =\left(\operatorname{int}\left(\mathrm{cl}\left(\mathrm{A}_{1} \times \mathrm{A}_{2}\right)\right)\right) \vee\left(\operatorname{cl}\left(\operatorname{int}\left(\mathrm{A}_{1} \times \mathrm{A}_{2}\right)\right)\right)
\end{aligned}
$$

Therefore $\mathrm{A}_{1} \times \mathrm{A}_{2}$ is fuzzy $\gamma$-open in the fuzzy product space $\mathrm{X} \times \mathrm{Y}$.

Theorem 3.12: Let $(X, \tau)$ and $(Y, \sigma)$ be any two fuzzy topological spaces such that $X$ is product related to $Y$. Then the product $A_{1} \times A_{2}$ of a fuzzy $\gamma$-semi open set $A_{1}$ of $X$ and a fuzzy $\gamma$-semi open set $A_{2}$ of $Y$ is fuzzy $\gamma$ semi open set of the fuzzy product space $\mathrm{X} \times \mathrm{Y}$.

\section{Proof:}

Let $A_{1}$ be a fuzzy $\gamma$-semi open subset of $X$ and $A_{2}$ be a fuzzy $\gamma$-semi open subset of $Y$. Then by using Theorem 3.3, we have $A_{1} \leq \operatorname{cl}\left(\gamma\right.$-int $\left.\left(A_{1}\right)\right)$ and $A_{2} \leq \operatorname{cl}\left(\gamma\right.$-int $\left.\left(A_{2}\right)\right)$. This implies that, $\mathrm{A}_{1} \times \mathrm{A}_{2} \leq \mathrm{cl}\left(\gamma\right.$-int $\left.\left(\mathrm{A}_{1}\right)\right) \times \mathrm{cl}$ $\left(\gamma\right.$-int $\left.\left(\mathrm{A}_{2}\right)\right)$.By Lemma $2.4(1), \mathrm{A}_{1} \times \mathrm{A}_{2} \leq \mathrm{cl}\left(\gamma\right.$-int $\left(\mathrm{A}_{1}\right) \times\left(\gamma\right.$-int $\left.\left(\mathrm{A}_{2}\right)\right)$ 
By Theorem 3.11, $A_{1} \times A_{2} \leq \mathrm{cl}\left(\gamma\right.$-int $\left.\left(A_{1} \times A_{2}\right)\right)$.Therefore $A_{1} \times A_{2}$ is fuzzy $\gamma$-semi open set in the fuzzy product space $\mathrm{X} \times \mathrm{Y}$.

\section{Fuzzy $\gamma$ - semi closed sets}

In this section we introduce the concept of fuzzy $\gamma$-semi closed sets in a fuzzy topological space.

Definition 4.1: Let A be a fuzzy subset of a fuzzy topological space $(X, \tau)$. Then A is called fuzzy $\gamma$-semi closed set of $X$ if there exist a fuzzy $\gamma$-closed set $\gamma$-c such that int $(\gamma-c) \leq A \leq \gamma-c$.

Theorem 4.2 : Let A and B be any two fuzzy subset of a fuzzy topological space (X, $\tau)$ and $\quad \gamma$-int(A) $\leq$ B $\leq \gamma$-cl(A). If A is a fuzzy $\gamma$-semi closed set then so is B.

Proof:

Let $A$ be a fuzzy subset of $X$ and $\gamma$-int $(A) \leq B \leq \gamma$-cl(A). If A is a fuzzy $\gamma$-semi closed set, then by Definition 4.1, there exists a fuzzy $\gamma$-closed set $\gamma$-c such that int $(\gamma$-c $) \leq \mathrm{A} \leq \gamma$-c. It follows that int $(\gamma$-c $) \leq \gamma$-int $(\mathrm{A}) \leq \mathrm{A} \leq \gamma$-cl $(\mathrm{A}) \leq \gamma$-c and hence int $(\gamma$-c) $\leq \mathrm{B} \leq \gamma$-c. Thus B is fuzzy $\gamma$-semi closed.

Theorem 4.3: A fuzzy subset $A$ of a fuzzy topological space $(X, \tau)$ is fuzzy $\gamma$-semi closed if and only if $A \geq$ int $(\gamma-\mathrm{cl}(\mathrm{A}))$.

Proof :

Let $\mathrm{A} \geq \operatorname{int}(\gamma$-cl(A)). Then for $\gamma$-c $=\gamma$-cl(A), we have $\mathrm{A} \leq \gamma$-cl(A). Therefore int $(\gamma$-cl(A)) $\leq \mathrm{A} \leq \gamma-$ cl(A). Conversely let A be fuzzy $\gamma$-semi closed. Then by Definition 4.1, there exists a fuzzy $\gamma$-closed set $\gamma$-c such that int $(\gamma-\mathrm{c}) \leq \mathrm{A} \leq \gamma$-c. But $\gamma$-cl(A) $\leq \gamma-\mathrm{c}$ and int $(\gamma-\mathrm{cl}(\mathrm{A})) \leq \operatorname{int}(\gamma-\mathrm{c})$ and thus int $(\gamma-\mathrm{cl}(\mathrm{A})) \leq \operatorname{int}(\gamma-\mathrm{c}) \leq \mathrm{A}$. Hence $\mathrm{A} \geq \operatorname{int}(\gamma-\operatorname{cl}(\mathrm{A}))$.

Proposition 4.4: $\quad$ Let $(X, \tau)$ be a fuzzy topological space and A be a fuzzy subset of $X$. Then A is fuzzy $\gamma$-semi closed if and only if $A^{c}$ is fuzzy $\gamma$-semi open.

Proof :

Let $\mathrm{A}$ be a fuzzy $\gamma$-semi closed subset of $\mathrm{X}$. Then by Theorem 4.3, $\mathrm{A} \geq$ int $(\gamma$-cl(A)). Taking complement on both sides, we get $A^{\mathrm{c}} \leq(\operatorname{int}(\gamma-\operatorname{cl}(\mathrm{A})))^{\mathrm{c}}=\mathrm{cl}(\gamma-\mathrm{cl}(\mathrm{A}))^{\mathrm{c}}$. By using Properties $2.8(\mathrm{~b}), \mathrm{A}^{\mathrm{c}} \leq \mathrm{cl}(\gamma$-int $\left(A^{c}\right)$ ). By Theorem 3.3, we have $A^{c}$ is fuzzy $\gamma$-semi open.

Conversely let $\mathrm{A}^{\mathrm{c}}$ is fuzzy $\gamma$-semi open. By Theorem 3.3, $\mathrm{A}^{\mathrm{c}} \leq \mathrm{cl}\left(\gamma\right.$-int $\left.\left(\mathrm{A}^{\mathrm{c}}\right)\right)$. Taking complement on both sides we get, $\mathrm{A} \geq\left(\operatorname{cl}\left(\gamma-\operatorname{int}\left(\mathrm{A}^{\mathrm{c}}\right)\right)^{\mathrm{c}}=\operatorname{int}\left(\gamma \text {-int }\left(\mathrm{A}^{\mathrm{c}}\right)\right)^{\mathrm{c}}\right.$. By using Properties 2.8(a), $\mathrm{A} \geq \operatorname{int}(\gamma-\operatorname{cl}(\mathrm{A}))$. By Theorem 4.3, we have A is fuzzy $\gamma$-semi closed.

Remark 4.5: It is obvious that every fuzzy $\gamma$-closed set is fuzzy $\gamma$-semi closed and every fuzzy closed set is fuzzy $\gamma$-semi closed but the separate converses may not be true as shown by the following example.

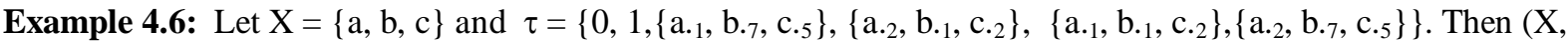
$\tau)$ is a fuzzy topological space. The family of all fuzzy closed sets of $\tau$ is $\quad \tau^{\mathrm{c}}=\left\{0,1,\left\{\mathrm{a} .9, \mathrm{~b}_{.3}, \mathrm{c}_{.5}\right\}\right.$,

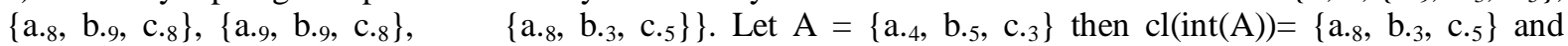
$\operatorname{int}(\operatorname{cl}(\mathrm{A}))=\left\{\mathrm{a}_{\cdot 2}, \mathrm{~b}_{\cdot 7}, \mathrm{c}_{5}\right\}$. Then $\operatorname{int}(\operatorname{cl}(\mathrm{A})) \wedge \operatorname{cl}(\operatorname{int}(\mathrm{A}))=\left\{\mathrm{a}_{.2}, \mathrm{~b}_{.3}, \mathrm{c}_{.5}\right\}$. By Definition 2.1(3), A is not fuzzy $\gamma-$ closed. Now let $\gamma-\operatorname{cl}(A)=\left\{a_{.5}, b_{.5}, c_{.5}\right\}$. Then $A \geq \operatorname{int}(\gamma-\operatorname{cl}(A))=\left\{a_{2}, b_{1}, c_{.2}\right\}$. Thus $A$ is fuzzy $\gamma$-semi closed.

The next example shows that every fuzzy $\gamma$-semi closed need not be fuzzy closed.

Example 4.7: Let $X=\{a, b, c\}$ and $\tau=\left\{0,1,\left\{a_{1}, b_{.7}, c_{.5}\right\},\left\{a_{.2}, b_{._{1}}, c_{.2}\right\},\left\{a_{.1}, b_{.1}, c_{.2}\right\},\left\{a_{2}, b_{.7}, c_{.5}\right\}\right\}$. Then (X, $\tau)$ is a fuzzy topological space. The family of all fuzzy closed sets of $\tau$ is $\quad \tau^{\mathrm{c}}=\left\{0,1,\left\{\mathrm{a} .9, \mathrm{~b}_{.3}, \mathrm{c} .5\right\},\{\mathrm{a} .8\right.$, b.9, c. $\left.\left.{ }^{8}\right\},\left\{a .9, b_{.9}, c_{.8}\right\},\left\{a_{.8}, b_{.3}, c_{.5}\right\}\right\}$. Let $A=\left\{a_{.4}, b_{.5}, c_{.3}\right\}$. Then $\left.\gamma-\operatorname{cl}(A)\right)=\left\{a_{.5}, b_{.5}, c_{.5}\right\}$ and $\operatorname{int}(\gamma-\operatorname{cl}(A))=$ $\left\{\mathrm{a} \cdot 2, \mathrm{~b}_{1}, \mathrm{c}_{2}\right\}$. That shows $\mathrm{A} \geq \operatorname{int}(\gamma-\mathrm{cl}(\mathrm{A}))$, it follows that $\mathrm{A}$ is fuzzy $\gamma$-semi closed. But $\mathrm{A}$ is not a fuzzy closed set.

It follows that every fuzzy semi closed set is fuzzy $\gamma$-semi closed but the converse may not be true as shown by the following example.

Example 4.8: Let $X=\{a, b\}$ and $\tau=\left\{0,1,\left\{a_{.8}, b_{.7}\right\}\right\}$. Then $(X, \tau)$ is a fuzzy topological space. The family of all fuzzy closed sets of $\tau$ is $\tau^{\mathrm{c}}=\left\{0,1,\left\{\mathrm{a}_{2}, \mathrm{~b}_{3}\right\}\right\}$. Let $\mathrm{A}=\left\{\mathrm{a}_{\cdot 4}, \mathrm{~b}_{5}\right\}$. Then $\gamma-\mathrm{cl}(\mathrm{A})=\left\{\mathrm{a}_{5}, \mathrm{~b}_{5}\right\}$ and $\operatorname{int}(\gamma-\mathrm{cl}(\mathrm{A}))=$ $\{0\}$. It shows that $\mathrm{A} \geq \operatorname{int}(\gamma$-cl $(\mathrm{A}))$. By using Theorem 4.3, A is fuzzy $\gamma$-semi closed.Now int $(\mathrm{cl}(\mathrm{A}))=\{1\}$. That shows $\mathrm{A} \geq \operatorname{int}(\mathrm{cl}(\mathrm{A}))$. Hence $\mathrm{A}$ is not a fuzzy semi closed set.

Theorem 4.9: Let $(X, \tau)$ be a fuzzy topological space. Then the intersection of two fuzzy $\gamma$-semi closed sets is fuzzy $\gamma$-semi closed set in the fuzzy topological space $(X, \tau)$.

Proof:

Let $A_{1}$ and $A_{2}$ be two fuzzy $\gamma$-semi closed sets. By Theorem 4.3, we have $\quad A_{1} \geq \operatorname{int}(\gamma-$ $\left.\operatorname{cl}\left(A_{1}\right)\right)$ and $A_{2} \geq \operatorname{int}\left(\gamma-\operatorname{cl}\left(A_{2}\right)\right)$. Therefore $A_{1} \wedge A_{2} \geq \operatorname{int}\left(\gamma-\operatorname{cl}\left(A_{1}\right)\right) \wedge \operatorname{int}\left(\left(\gamma-\operatorname{cl}\left(A_{2}\right)\right)=\operatorname{int}\left(\gamma-\operatorname{cl}\left(A_{1}\right) \wedge\left(\gamma-\operatorname{cl} A_{2}\right)\right)\right.$. By using Properties 2.10(6), $A_{1} \wedge A_{2} \geq \operatorname{int}\left(\gamma\right.$-cl $\left.\left(A_{1} \wedge A_{2}\right)\right)$. Hence $A_{1} \wedge A_{2}$ is fuzzy $\gamma$-semi closed.

The union of two fuzzy $\gamma$-semi closed sets is need not be fuzzy $\gamma$-semi closed set in the fuzzy topological space $\mathrm{X}$ as shown by the following example.

Example 4.10: Let $X=\{a, b, c\}$ and $\tau=\left\{0,1,\left\{a_{.5}, b_{.2}, c_{.7}\right\},\left\{a .7, b .8, c_{.3}\right\},\left\{a_{.5}, b_{.2}, c_{.3}\right\}, \quad\left\{a_{.7}, b_{8}\right.\right.$, c. 7$\}$. Then $(X, \tau)$ is a fuzzy topological space. The family of all fuzzy closed sets of $\tau$ is $\tau^{c}=\left\{0,1,\left\{a_{.5}, b_{8}\right.\right.$, 
$\left.\left.c_{.3}\right\},\left\{a_{.3}, b_{.2}, c_{.7}\right\},\left\{a_{.5}, b_{.8}, c_{.7}\right\},\left\{a_{.3}, b_{.2}, c_{.3}\right\}\right\}$. Let $A=\left\{a_{.6}, b_{.7}, c_{.6}\right\}$ and $\gamma-\operatorname{cl}(\mathrm{A})=\{\mathrm{a} \cdot 6, \mathrm{~b} .8, \mathrm{c} .5\}$. Then we get $\operatorname{int}(\gamma-\mathrm{cl}(\mathrm{A}))=\left\{\mathrm{a}_{.5}, \mathrm{~b}_{.2}, \mathrm{c}_{3}\right\}$.Thus by Theorem 4.3, $\mathrm{A}$ is fuzzy $\gamma$-semi closed. Let $\mathrm{B}=\left\{\mathrm{a}_{.5}, \mathrm{~b}_{.8}, \mathrm{c}_{.5}\right\}$ and $\gamma$ $\mathrm{cl}(\mathrm{B})=\left\{\mathrm{a} .5, \mathrm{~b} .8, \mathrm{c}_{6}\right\}$. Then we get fuzzy $\gamma$-semi closed. $\operatorname{int}(\gamma-\mathrm{cl}(\mathrm{B}))=\left\{\mathrm{a}_{.5}, \mathrm{~b}_{2}, \mathrm{c}_{3}\right\}$. Thus by Theorem 4.3, B is $(\mathrm{A} \vee \mathrm{B}))=$ Now $A \vee B=\left\{a_{.}, b_{.}, c_{.6}\right\}$ and $\gamma-c l(A \vee B)=\left\{a_{-6}, b_{.8}, c_{.8}\right\}$. Then int $(\gamma-c l$ $\vee \mathrm{B}$ is not fuzzy $\gamma$-semi closed.

Theorem 4.11: Let $(X, \tau)$ be a fuzzy topological space and let $\left\{A_{\alpha}\right\}_{\alpha \in \Delta}$ be a collection of fuzzy $\gamma$-semi closed sets in a fuzzy topological space X. Then $\hat{\alpha \in \Delta} \mathrm{A}_{\alpha}$ is fuzzy $\gamma$-semi closed for each $\alpha \in \Delta$.

Proof:

Let $\Delta$ be a collection of fuzzy $\gamma$-semi closed sets of a fuzzy topological space $(\mathrm{X}, \tau)$. Then by Theorem 4.3, for each $\alpha \in \Delta, \mathrm{A}_{\alpha} \geq \operatorname{int}\left(\gamma-\operatorname{cl}\left(\mathrm{A}_{\alpha}\right)\right)$. Then $\hat{\alpha \in \Delta} \mathrm{A}_{\alpha} \geq \hat{\alpha \in \Delta}\left(\operatorname{int}\left(\gamma-\operatorname{cl}\left(\mathrm{A}_{\alpha}\right)\right)\right) \geq \operatorname{int} \hat{\alpha \in \Delta}\left(\gamma-\operatorname{cl}\left(\mathrm{A}_{\alpha}\right)\right)$. By using Properties 2.6, $\hat{\alpha \in \Delta}^{\wedge} \mathrm{A}_{\alpha} \geq \operatorname{int}\left(\gamma-\operatorname{cl}\left(\hat{\alpha \in \Delta}\left(\mathrm{A}_{\alpha}\right)\right)\right)$. Thus arbitrary intersection of fuzzy $\gamma$-semi closed set is fuzzy $\gamma$-semi closed.

Theorem 4.12: Let $(X, \tau)$ and $(Y, \sigma)$ be any two fuzzy topological spaces such that $X$ is product related to $Y$. Then the product $A_{1} \times A_{2}$ of fuzzy $\gamma$-closed set $A_{1}$ of $X$ and a fuzzy $\gamma$-closed set $A_{2}$ of $Y$ is fuzzy $\gamma$-closed set of the fuzzy product space $\mathrm{X} \times \mathrm{Y}$.

Proof:

Let $A_{1}$ be a fuzzy $\gamma$-closed subset of $X$ and $A_{2}$ be a fuzzy $\gamma$-closed subset of $Y$. Then by Definition 2.1, we have $A_{1} \geq \operatorname{int}\left(\operatorname{cl}\left(A_{1}\right)\right) \wedge \operatorname{cl}\left(\operatorname{int}\left(A_{1}\right)\right)$ and $A_{2} \geq \operatorname{int}\left(\operatorname{cl}\left(A_{2}\right)\right) \wedge \operatorname{cl}\left(\operatorname{int}\left(A_{2}\right)\right)$. Now $A_{1} \times A_{2} \geq\left(\operatorname{int}\left(\operatorname{cl}\left(A_{1}\right)\right) \wedge\right.$ $\left.\operatorname{cl}\left(\operatorname{int}\left(\mathrm{A}_{1}\right)\right)\right) \times\left(\operatorname{int}\left(\mathrm{cl}\left(\mathrm{A}_{2}\right)\right) \wedge \operatorname{cl}\left(\operatorname{int}\left(\mathrm{A}_{2}\right)\right)\right)$. By using Lemma 2.5,

$A_{1} \times A_{2} \geq\left(\right.$ int $\left(\operatorname{cl}\left(A_{1} \times A_{2}\right)\right) \wedge \operatorname{cl}\left(\right.$ int $\left.\left(A_{1} \times A_{2}\right)\right)$ ). Therefore $A_{1} \times A_{2}$ is fuzzy $\gamma$-closed in the fuzzy product space $\mathrm{X} \times \mathrm{Y}$.

Theorem 4.13: Let $(X, \tau)$ and $(Y, \sigma)$ be any two fuzzy topological spaces such that $X$ is product related to $Y$. Then the product $A_{1} \times A_{2}$ of fuzzy $\gamma$-semi closed set $A_{1}$ of $X$ and a fuzzy $\gamma$-semi closed set $A_{2}$ of $Y$ is fuzzy $\gamma$ semi closed set of the fuzzy product space $\mathrm{X} \times \mathrm{Y}$.

Proof:

Let $A_{1}$ be a fuzzy $\gamma$-semi closed subset of $X$ and $A_{2}$ be a fuzzy $\gamma$-semi closed subset of $Y$. Then by Theorem 4.3, we have $A_{1} \geq \operatorname{int}\left(\gamma-\operatorname{cl}\left(A_{1}\right)\right)$ and $A_{2} \geq \operatorname{int}\left(\gamma-\operatorname{cl}\left(A_{2}\right)\right)$. Now $A_{1} \times A_{2} \geq \operatorname{int}\left(\gamma-\operatorname{cl}\left(A_{1}\right)\right) \times \operatorname{int}\left(\gamma-\operatorname{cl}\left(A_{2}\right)\right)$. By using Lemma 2.4(2), $A_{1} \times A_{2} \geq \operatorname{int}\left(\gamma-c l\left(A_{1}\right) \times \gamma-c l\left(A_{2}\right)\right)$. By using the Theorem 4.12, we get $A_{1} \times A_{2} \geq$ $\operatorname{int}(\gamma-\mathrm{cl}(\mathrm{A} 1 \times \mathrm{A} 2))$.

Therefore $A_{1} \times A_{2}$ is fuzzy $\gamma$-semi closed in the fuzzy product space $X \times Y$.

\section{Fuzzy $\gamma$-semi interior}

In this section we introduce the concept of fuzzy $\gamma$-semi interior and

their properties in a fuzzy topological space.

Definition 5.1: Let $(X, \tau)$ be a fuzzy topological space. Then for a fuzzy subset A of $X$, the fuzzy $\gamma$-semi interior of A (briefly $\gamma$-sint (A)) is the union of all fuzzy $\gamma$-semi open sets of X contained in A. That is, $\gamma$-sint $(A)=\vee$ $\{\mathrm{B}: \mathrm{B} \leq \mathrm{A}, \mathrm{B}$ is fuzzy $\gamma$-semi open in $\mathrm{X}\}$

Proposition 5.2 : Let $(\mathrm{X}, \tau)$ be a fuzzy topological space. Then for any fuzzy subsets A and B of a fuzzy topological $\mathrm{X}$ we have

(i) $\quad \gamma$-sint $(\mathrm{A}) \leq \mathrm{A}$

(ii) $\quad \mathrm{A}$ is fuzzy $\gamma$-semi open $\Leftrightarrow \gamma$-sint $(\mathrm{A})=\mathrm{A}$

(iii) $\quad \gamma$-sint $(\gamma-\operatorname{sint}(\mathrm{A}))=\gamma$-sint $(\mathrm{A})$

(iv) $\quad$ if $\mathrm{A} \leq \mathrm{B}$ then $\gamma$-sint $(\mathrm{A}) \leq \gamma$-sint (B)

Proof:

(i) follows from Definition 5.1.

(ii) Let A be fuzzy $\gamma$-semi open.

Then $\mathrm{A} \leq \gamma$-sint (A). By using (i) we get $\mathrm{A}=\gamma$-sint (A).

Conversely assume that $\mathrm{A}=\gamma$-sint (A). By using Definition 5.1, A is fuzzy $\gamma$-semi open. Thus (ii) is proved.

(iii) $\quad$ By using (ii) we get $\gamma$-sint $(\gamma$-sint (A)) $=\gamma$-sint (A). This proves (iii).

(iv) $\quad$ Since $A \leq B$, by using (i) $\gamma$-sint $(\mathrm{A}) \leq \mathrm{A} \leq \mathrm{B}$. That is $\gamma$-sint $(\mathrm{A}) \leq \mathrm{B}$.

By (iii), $\gamma$-sint $(\gamma$-sint (A)) $\leq \gamma$-sint(B). Thus $\gamma$-sint (A) $\leq \gamma$-sint (B). This proves (iv).

Theorem 5.3: Let $(X, \tau)$ be a fuzzy topological space. Then for any fuzzy subset $A$ and $B$ of a fuzzy topological space, we have

(i) $\quad \gamma$-sint $(\mathrm{A} \wedge \mathrm{B})=(\gamma-\operatorname{sint} \mathrm{A}) \wedge(\gamma$-sint $\mathrm{B})$ 
Proof:

(ii) $\quad \gamma$-sint $(A \vee B) \geq(\gamma-\operatorname{sint} A) \vee(\gamma-\operatorname{sint} B)$

Since $\mathrm{A} \wedge \mathrm{B} \leq \mathrm{A}$ and $\mathrm{A} \wedge \mathrm{B} \leq \mathrm{B}$, by using Proposition 5.2(iv), we get

$\gamma$-sint $(\mathrm{A} \wedge \mathrm{B}) \leq \gamma$-sint $(\mathrm{A})$ and $\gamma$-sint $(\mathrm{A} \wedge \mathrm{B}) \leq \gamma$-sint $(\mathrm{B})$. This implies that $\operatorname{sint} \mathrm{A}) \wedge(\gamma-\operatorname{sint} \mathrm{B})$ (1).

By using Proposition5.2(i), we have $\gamma-\operatorname{sint}(\mathrm{A}) \leq \mathrm{A}$ and $\gamma-\operatorname{sint}(\mathrm{B}) \leq \mathrm{B}$. This implies that $\gamma-\operatorname{sint}(\mathrm{A}) \wedge \gamma$-sint $(\mathrm{B})$ $\leq \mathrm{A} \wedge \mathrm{B}$. Now applying Proposition 5.2(iv),

we get $\gamma$-sint $((\gamma-\operatorname{sint}(\mathrm{A}) \wedge \gamma$-sint $(\mathrm{B})) \leq \gamma$-sint $(\mathrm{A} \wedge \mathrm{B})$.

By (1), $\gamma$-sint $(\gamma$-sint $(\mathrm{A})) \wedge \gamma-\operatorname{sint}(\gamma-\operatorname{sint}(\mathrm{B})) \leq \gamma$-sint $(\mathrm{A} \wedge \mathrm{B})$. By Proposition 5.2(iii), $\gamma$-sint $(\mathrm{A}) \wedge \gamma$-sint $(\mathrm{B}) \leq$ $\gamma$-sint $(\mathrm{A} \wedge \mathrm{B})$-----------------(2).

$\gamma$-sint (B). This implies(i).

From $(1)$ and $(2), \gamma-\operatorname{sint}(\mathrm{A} \wedge \mathrm{B})=\gamma-\operatorname{sint}(\mathrm{A}) \wedge$

Since $A \leq A \vee B$ and $B \leq A \vee B$, by using Proposition 5.2(iv), we have $\gamma$-sint $(A) \leq \gamma$-sint $(A \vee B)$ and $\gamma$ $\operatorname{sint}(\mathrm{B}) \leq \gamma$-sint $(\mathrm{A} \vee \mathrm{B})$. This implies that $\gamma$-sint $(\mathrm{A}) \vee \gamma$-sint $(\mathrm{B}) \leq \gamma$-sint $(\mathrm{A} \vee \mathrm{B})$. Hence (ii).

The following example shows that the equality need not be hold in Theorem 5.3(ii).

Example 5.4: Let $\mathrm{X}=\{\mathrm{a}, \mathrm{b}, \mathrm{c}\}$ and $\tau=\left\{0,1,\left\{\mathrm{a}_{.5}, \mathrm{~b}_{.3}, \mathrm{c}_{.7}\right\},\left\{\mathrm{a}_{.2}, \mathrm{~b}_{.4}, \mathrm{c}_{.4}\right\},\left\{\mathrm{a}_{2}, \mathrm{~b}_{.3}, \mathrm{c}_{.4}\right\},\left\{\mathrm{a} .5_{5}, \mathrm{~b}_{.4}, \mathrm{c}_{.7}\right\}\right\}$. Then (X, $\tau)$ is a fuzzy topological space. The family of all fuzzy closed sets of $\tau$ is $\tau^{c}=\left\{0,1,\left\{a .5, b_{.7}, c_{.3}\right\},\left\{a_{.8}, b_{.6}, c_{.6}\right\}\right.$, $\left.\left\{a_{.8}, b_{.7}, c_{.6}\right\},\left\{a_{.5}, b_{.6}, c_{.3}\right\}\right\}$. Consider $A=\left\{a_{.4}, b_{.3}, c_{.4}\right\}$ and $\quad B=\left\{a_{.3}, b_{.7}, c_{.4}\right\}$. Then $\gamma$-sint $(A)=\left\{a_{.3}\right.$, $\left.\mathrm{b}_{3}, \mathrm{c}_{.4}\right\}$ and $\gamma$-sint $(\mathrm{B})=\left\{\mathrm{a} .2_{2}, \mathrm{~b}_{.4}, \mathrm{c}_{.4}\right\}$. That implies $\gamma$-sint $(\mathrm{A}) \vee \gamma$-sint $(\mathrm{B})=\left\{\mathrm{a}_{\cdot 3}, \mathrm{~b}_{4}, \mathrm{c}_{\cdot 4}\right\}$. Now $A \vee B=\left\{a_{.4}, b_{.7}, c_{.4}\right\}$, it follows that $\gamma$-sint $(A \vee B)=\left\{a .4, b_{.5}, c_{.4}\right\}$. Then $\gamma$-sint $(A \vee B) \not \gamma$-sint $(A) \vee \gamma$-sint $(B)$. Thus $\gamma$-sint $(A \vee B) \neq \gamma$-sint $(A) \vee \quad \gamma$-sint $(B)$.

\section{Fuzzy $\gamma$-semi closure}

In this section we introduce the concept of fuzzy $\gamma$-semi closure in a fuzzy topological space.

Definition 6.1: Let $(X, \tau)$ be a fuzzy topological space. Then for a fuzzy subset $A$ of $X$, the fuzzy $\gamma$-semi closure of A (briefly $\gamma$-scl (A)) is the intersection of all fuzzy $\gamma$-semi closed sets contained in A. That is, $\gamma$-scl $(\mathrm{A})=\wedge\{\mathrm{B}: \mathrm{B} \geq \mathrm{A}, \mathrm{B}$ is fuzzy $\gamma$-semi closed $\}$.

Proposition 6.2: Let $(X, \tau)$ be a fuzzy topological space. Then for any fuzzy subsets A of $X$, we have

i. $\quad(\gamma-\operatorname{sint}(\mathrm{A}))^{\mathrm{c}}=\gamma-\operatorname{scl}\left(\mathrm{A}^{\mathrm{c}}\right)$ and

ii. $\quad(\gamma-\operatorname{scl}(\mathrm{A}))^{\mathrm{c}}=\gamma-\operatorname{sint}\left(\mathrm{A}^{\mathrm{c}}\right)$

Proof:

By using Definition 5.1, $\gamma$-sint $(\mathrm{A})=\vee\{\mathrm{B}: \mathrm{B} \leq \mathrm{A}, \mathrm{B}$ is fuzzy $\gamma$-semi open $\}$. Taking complement on both sides, we get $[\gamma \text {-sint }(A)]^{c}=(\sup \{B: B \leq A, B \text { is fuzzy } \gamma \text {-semi open }\})^{c}=\inf \left\{B^{c}: B^{c} \geq A^{c}, B^{c}\right.$ is fuzzy $\gamma$-semi

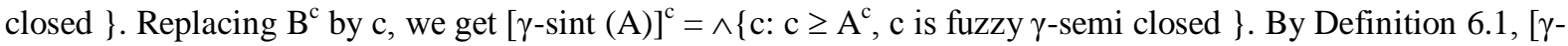
$\operatorname{sint}(A)]^{c}=\gamma-\operatorname{scl}\left(A^{c}\right)$. This proves(i).

By using(i), $\left[\gamma \text {-sint }\left(A^{c}\right)\right]^{c}=\gamma$-scl $\left(A^{c}\right)^{c}=\gamma$-scl $(A)$. Taking complement on both sides, we set $\gamma$-sint $\left(A^{c}\right)=[\gamma-\operatorname{scl}(A)]^{c}$. Hence proved (ii).

Proposition 6.3: Let $(X, \tau)$ be a fuzzy topological space. Then for a fuzzy subset A and B of a fuzzy topological space $X$, we have

(i) $\quad \mathrm{A} \leq \gamma-\operatorname{scl}(\mathrm{A})$

(ii) $\quad \mathrm{A}$ is fuzzy $\gamma$-semi closed $\Leftrightarrow \gamma$-scl (A) $=\mathrm{A}$.

(iii) $\quad \gamma$-scl $(\gamma$-scl (A)) $=\gamma$-scl (A).

(iv) $\quad$ if $\mathrm{A} \leq \mathrm{B}$ then $\gamma$-scl $(\mathrm{A}) \leq \gamma$-scl (B).

Proof:

(i) The proof of (i) follows from the Definition 6.1.

(ii) Let A be fuzzy $\gamma$-semi closed subset in $\mathrm{X}$. By using Proposition 4.4, $\mathrm{A}^{\mathrm{c}}$ is fuzzy $\gamma$-semi open. By using Proposition 6.2(ii), $\gamma-\operatorname{sint}\left(\mathrm{A}^{\mathrm{c}}\right)=\mathrm{A}^{\mathrm{c}} \Leftrightarrow[\gamma-\operatorname{scl}(\mathrm{A})]^{\mathrm{c}}=\mathrm{A}^{\mathrm{c}} \Leftrightarrow \gamma$-scl $(\mathrm{A})=\mathrm{A}$. Thus proved (ii).

(iii) $\quad$ By using (ii), $\gamma-\operatorname{scl}(\gamma-\operatorname{scl}(\mathrm{A}))=\gamma-\operatorname{scl}(\mathrm{A})$. This proves (iii).

(iv) $\quad$ Suppose $\mathrm{A} \leq \mathrm{B}$. Then $\mathrm{B}^{\mathrm{c}} \leq \mathrm{A}^{\mathrm{c}}$. By using Proposition 5.2(iv),

$\gamma$-sint $\left(B^{c}\right) \leq \gamma$-sint $\left(A^{c}\right)$. Taking complement on both sides, we get

$\left[\gamma-\operatorname{sint}\left(\mathrm{B}^{\mathrm{c}}\right)\right]^{\mathrm{c}} \geq\left[\gamma \text {-sint }\left(\mathrm{A}^{\mathrm{c}}\right)\right]^{\mathrm{c}}$. By proposition 6.2(ii),

$\gamma$-scl (B) $\geq \gamma$-scl(A). This proves (iv).

Proposition 6.4: Let $A$ be a fuzzy set in a fuzzy topological space $X$. Then $\operatorname{int}(A) \leq \operatorname{sint}(A) \leq \gamma$-int $(A) \leq \gamma$ $\operatorname{sint}(\mathrm{A}) \leq \mathrm{A} \leq \gamma-\operatorname{scl}(\mathrm{A}) \leq \gamma-\operatorname{cl}(\mathrm{A}) \leq \operatorname{scl}(\mathrm{A}) \leq \operatorname{cl}(\mathrm{A})$.

Proof: It follows from the Definitions of corresponding operators.

Proposition 6.5: Let $(X, \tau)$ be a fuzzy topological space. Then for a fuzzy subset A and B of a fuzzy topological space $\mathrm{X}$, we have 
(i) $\quad \gamma$-scl $(\mathrm{A} \vee \mathrm{B})=\gamma$-scl $(\mathrm{A}) \vee \gamma$-scl $(\mathrm{B})$ and

(ii) $\quad \gamma-\operatorname{scl}(\mathrm{A} \wedge \mathrm{B}) \leq \gamma-\operatorname{scl}(\mathrm{A}) \wedge \gamma$-scl (B).

Proof:

Since $\gamma$-scl $(A \vee B)=\gamma-\operatorname{scl}\left[(A \vee B)^{c}\right]^{c}$, by using Proposition 6.2(i), we have

$\gamma$-scl $(A \vee B)=\left[\gamma-\operatorname{sint}(A \vee B)^{c}\right]^{c}=\left[\gamma \text {-sint }\left(A^{c} \wedge B^{c}\right)\right]^{c}$. Again using Proposition 5.3(i), we have $\gamma$-scl $(A \vee B)=[\gamma-\operatorname{sint}$ $\left(A^{c}\right) \wedge \gamma$-sint $\left.\left.\left(B^{c}\right)\right]^{c}=\left[\gamma-\operatorname{sint}\left(A^{c}\right)\right]^{c} \vee\left[\gamma-\operatorname{sint}\left(B^{c}\right)\right)\right]^{c}$. By using Proposition 6.2(i), we have $\gamma-\operatorname{scl}(A \vee B)=\gamma$-scl $\left(A^{c}\right)^{c}$ $\vee \gamma$-scl $\left(\mathrm{B}^{\mathrm{c}}\right)^{\mathrm{c}}=\gamma$-scl $(\mathrm{A}) \vee \gamma$-scl $(\mathrm{B})$. Thus proved (i).

Since $\mathrm{A} \wedge \mathrm{B} \leq \mathrm{A}$ and $\mathrm{A} \wedge \mathrm{B} \leq \mathrm{B}$, by using Proposition 6.3(iv), $\gamma$-scl $(\mathrm{A} \wedge \mathrm{B}) \leq \gamma$-scl(A) and $\gamma$-scl $(\mathrm{A} \wedge \mathrm{B})$ $\leq \gamma$-scl $(\mathrm{B})$. This implies that $\gamma$-scl $(\mathrm{A} \wedge \mathrm{B}) \leq \gamma$-scl $(\mathrm{A}) \wedge \gamma$-scl $(\mathrm{B})$. This proves(ii).

The following example shows that $\gamma$-scl $(A \wedge B)$ need not be equal to $\gamma-\operatorname{scl}(A) \wedge \gamma$-scl(B).

Example 6.6: Let $X=\{a, b, c\}$ and $\tau=\left\{0,1,\left\{a_{.1}, b_{.7}, c_{.5}\right\},\left\{a_{.2}, b_{.1}, c_{.2}\right\},\left\{a_{.1}, b_{.1}, c_{.2}\right\}, \quad\left\{a_{.2}, b_{.7}\right.\right.$, $\left.\left.c_{.5}\right\}\right\}$. Then $(X, \tau)$ is a fuzzy topological space. The family of all fuzzy closed sets of $\tau$ is $\tau^{c}=\{0,1,\{a .9, b .3$, $\left.c_{.5}\right\},\left\{a_{.8}, b_{.9}, c_{.8}\right\},\left\{a_{.9}, b_{.9}, c_{.8}\right\},\left\{a_{.8}, b_{.3}, c_{.5}\right\}$. Consider $A=\left\{a_{.4}, b_{.5}, c_{.3}\right\}$ and $B=\left\{a_{.9}, b_{.5}, c_{.5}\right\}$. Then $\gamma-\operatorname{scl}(A)$ $=\left\{a_{.5}, b_{.5}, c_{.5}\right\}$ and $\gamma$-scl $(B)=\left\{a_{.9}, b_{.5}, c_{.2}\right\}$. Also $\gamma$-scl $(A) \wedge \gamma$-scl $(B)=\left\{a_{.5}, b_{.5}, c_{.2}\right\}$. Now $A \wedge B=\left\{a_{.4}, b_{.5}\right.$, $\left.c_{.2}\right\}$ and $\gamma$-scl $(A \wedge B)=\left\{a_{.4}, b_{.5}, c_{.3}\right\}$. Thus $\gamma$-scl $(A) \wedge \gamma-\operatorname{scl}(B) \neq \gamma-\operatorname{scl}(A \wedge B)$.

Theorem 6.7: Let $(X, \tau)$ be a fuzzy topological space. Then for a fuzzy subset $A$ and $B$ of $X$ we have,

(i) $\quad \gamma$-scl (A) $\geq A \vee \gamma-\operatorname{scl}(\gamma-\operatorname{sint}(\mathrm{A}))$.

(ii) $\quad \gamma$-sint $(\mathrm{A}) \leq \mathrm{A} \wedge \gamma$-sint $(\gamma-\operatorname{scl}(\mathrm{A}))$.

(iii) $\quad$ int $(\gamma-\operatorname{scl}(\mathrm{A})) \leq \operatorname{int}(\mathrm{cl}(\mathrm{A}))$.

(iv) $\quad \operatorname{int}(\gamma-\operatorname{scl}(\mathrm{A})) \geq \operatorname{int}(\gamma-\operatorname{scl}(\gamma-\operatorname{sint}(\mathrm{A})))$.

Proof:

(i) By Proposition 6.3(i), A $\leq \gamma$-scl (A) ----------- (1).

Again using Proposition 5.2(i), $\gamma$-sint $(\mathrm{A}) \leq \mathrm{A}$.

Then $\gamma$-scl $(\gamma$-sint $(\mathrm{A}) \leq \gamma$ - scl (A) ------ (2).

By (1) \& (2) we have, $A \vee \gamma$-scl $(\gamma$-sint (A)) $\leq \gamma$-scl (A). This proves (i).

By Proposition 5.2(i), $\gamma$-sint (A) $\leq \mathrm{A}$----(1).

Again using proposition 6.3(i), $\mathrm{A} \leq \gamma$-scl (A).

Then $\gamma$-sint $(\mathrm{A}) \leq \gamma$-sint $(\gamma$-scl $(\mathrm{A}))---(2)$.

From (1) \& (2), we have $\gamma$-sint (A) $\leq \mathrm{A} \wedge \gamma$-sint $(\gamma$-scl (A)). This proves(ii).

(iii) By Proposition 6.4, $\gamma$-scl (A) $\leq \mathrm{cl}$ (A).

we get int $(\gamma-\operatorname{scl}(\mathrm{A})) \leq$ int $(\operatorname{cl}(\mathrm{A}))$.

(iv) $\quad$ By (i), $\gamma$-scl (A) $\geq A \vee \gamma-\operatorname{scl}(\gamma$-sint(A)). Then we have

int $(\gamma$-scl $(A) \geq \operatorname{int}(A \vee \gamma$-scl $(\gamma$-sint (A)) ). Since int $(A \vee B) \geq \operatorname{int}(A) \vee \operatorname{int}(B)$,

$\operatorname{int}(\gamma-\operatorname{scl}(\mathrm{A}) \geq \operatorname{int}(\mathrm{A}) \vee \operatorname{int}(\gamma-\operatorname{scl}(\gamma-\operatorname{sint}(\mathrm{A}))) \geq \operatorname{int}(\gamma-\operatorname{scl}(\gamma-\operatorname{sint}(\mathrm{A})))$.

The family of all fuzzy semi open (fuzzy semi closed, fuzzy strongly semi open, fuzzy strongly semi closed, fuzzy $\gamma$-semi open, fuzzy $\gamma$-semi closed, fuzzy $\gamma$-open, fuzzy $\gamma$-closed) sets of an fuzzy topological $\operatorname{space}(X, \tau)$ will be denoted by $\operatorname{Fso}(\tau)(\operatorname{Fscl}(\tau), \operatorname{Fsso}(\tau), \operatorname{Fsscl}(\tau), \operatorname{F\gamma so}(\tau), \operatorname{F\gamma scl}(\tau), \operatorname{F\gamma o}(\tau), \operatorname{F\gamma cl}(\tau))$.

Proposition 6.8: Let $(X, \tau)$ be a fuzzy topological space. Then

1) $\quad \operatorname{Fsscl}(\tau) \wedge \operatorname{Fscl}(\tau) \leq \operatorname{Frscl}(\tau)$

2) $\quad \operatorname{Fsso}(\tau) \wedge \operatorname{Fso}(\tau) \leq \operatorname{Frso}(\tau)$.

3) $\quad \operatorname{F\gamma o}(\tau) \wedge \operatorname{Fso}(\tau) \leq \operatorname{F\gamma } \operatorname{so}(\tau)$.

4) $\quad \operatorname{F\gamma cl}(\tau) \wedge \operatorname{Fscl}(\tau) \leq \operatorname{Frs}(\tau)$

Proof:

Let $A$ be a fuzzy subset of $\operatorname{Fsscl}(\tau) \wedge \operatorname{Fscl}(\tau)$. Then $A \in \operatorname{Fsscl}(\tau)$ and $A \in \operatorname{Fscl}(\tau)$. By the Definition of fuzzy strongly semi closed, $\mathrm{A} \geq \operatorname{cl}(\operatorname{int}(\operatorname{cl}(\mathrm{A}))) \geq \operatorname{int}(\operatorname{cl}(\mathrm{A})) \geq \operatorname{int}(\gamma-\operatorname{cl}(\mathrm{A}))$. By the Definition of fuzzy semi closed, $\mathrm{A} \geq \operatorname{int}(\mathrm{cl}(\mathrm{A})) \geq \operatorname{int}(\gamma-\mathrm{cl}(\mathrm{A}))$. Therefore $\mathrm{A} \geq \operatorname{int}(\gamma-\mathrm{cl}(\mathrm{A}))$. That is $\mathrm{A}$ is fuzzy $\gamma$-semi closed. This proves (1).

Let $A \in \operatorname{Fsso}(\tau) \wedge \operatorname{Fso}(\tau)$. Then $A \in \operatorname{Fsso}(\tau)$ and $A \in \operatorname{Fso}(\tau)$. By the Definition of fuzzy strongly semi open, $\mathrm{A} \leq \operatorname{int}(\operatorname{cl}(\operatorname{int}(\mathrm{A}))) \leq \operatorname{cl}(\operatorname{int}(\mathrm{A})) \leq \mathrm{cl}(\gamma$-int $(\mathrm{A}))$. Again using the Definition of fuzzy semi open, $\mathrm{A} \leq$ $\operatorname{cl}(\operatorname{int}(\mathrm{A})) \leq \operatorname{cl}(\gamma$-int $(\mathrm{A}))$. Therefore $\mathrm{A}$ is fuzzy $\gamma$-semi open. This proves (2).

Let $A \in \operatorname{F} \gamma o(\tau) \wedge \operatorname{Fso}(\tau)$. Then $A \in \operatorname{Fro}(\tau)$ and $A \in \operatorname{Fso}(\tau)$. By the Definition of fuzzy $\gamma$-open, $A \leq$ $\operatorname{cl}($ int $(\mathrm{A}) \vee \operatorname{int}(\mathrm{cl}(\mathrm{A})$. That is $\mathrm{A} \leq \operatorname{cl}($ int $\mathrm{A}) \leq \operatorname{cl}(\gamma$-int $(\mathrm{A}))$. Again using the Definition of fuzzy semi open, $\mathrm{A} \leq$ $\operatorname{cl}($ int $A)$. This implies that $\mathrm{A} \leq \mathrm{cl}(\gamma$-int $(\mathrm{A}))$. Therefore $\mathrm{A}$ is fuzzy $\gamma$-semi open. Hence proved (3).

Let $A \in \operatorname{F} \gamma \operatorname{cl}(\tau) \wedge \operatorname{Fscl}(\tau)$. Then $A \in \operatorname{F} \gamma \operatorname{cl}(\tau)$ and $A \in \operatorname{Fscl}(\tau)$. By the Definition of fuzzy $\gamma$-closed, $\mathrm{A} \geq \operatorname{int}(\mathrm{cl}(\mathrm{A})) \wedge \operatorname{cl}(\operatorname{int}(\mathrm{A}))$ that is $\mathrm{A} \geq \operatorname{int}(\mathrm{cl}(\mathrm{A}) \geq \operatorname{int}(\gamma-\operatorname{cl}(\mathrm{A}))$. Again by Theorem 4.3, $\mathrm{A} \geq \operatorname{int}(\mathrm{cl}(\mathrm{A}))$. This implies that $A \geq \operatorname{int}(\gamma-\mathrm{cl}(\mathrm{A}))$. Therefore $\mathrm{A}$ is fuzzy $\gamma$-semi closed. Hence proved (4). 
Definition 6.9: An fuzzy topological space (X, $\tau$ ) is fuzzy $\gamma$-SO-extremely disconnected if and only if $\gamma$-scl(A) is a fuzzy $\gamma$-semi open set, for each fuzzy $\gamma$-semi open set A of $(X, \tau)$.

Theorem 6.10: Let $(\mathrm{X}, \tau)$ be an fuzzy topological space. Then the following statements are equivalent:

(i) $\quad \mathrm{X}$ is $\gamma$-SO-extremely disconnected.

(ii) $\quad \gamma$-sint(A) is a fuzzy $\gamma$-semi closed set, for each fuzzy $\gamma$-semi closed set A of $\mathrm{X}$.

(iii) $\quad \gamma-\operatorname{scl}(\gamma-\operatorname{scl}(\mathrm{A}))^{\mathrm{c}}=(\gamma-\operatorname{scl}(\mathrm{A}))^{\mathrm{c}}$, for each fuzzy $\gamma$-semi open set $\mathrm{A}$ of $\mathrm{X}$.

(iv) $\quad \mathrm{B}=(\gamma-\operatorname{scl}(\mathrm{A}))^{\mathrm{c}}$ implies $\gamma-\operatorname{scl}(\mathrm{B})=(\gamma-\operatorname{scl}(\mathrm{A}))^{\mathrm{c}}$ for each pair of fuzzy $\gamma-$ semi open sets $\mathrm{A}, \mathrm{B}$ of $\mathrm{X}$.

\section{Proof:}

(i) $\Rightarrow$ (ii) Let $\mathrm{A}$ be a fuzzy $\gamma$-semi closed set of $\mathrm{X}$. Then $\mathrm{A}^{\mathrm{c}}$ is a fuzzy $\gamma$-semi open set. According to the assumption, $\gamma$-scl $\left(\mathrm{A}^{\mathrm{c}}\right)$ is fuzzy $\gamma$-semi open set. So $\gamma$-int $(\mathrm{A})$ is a fuzzy $\gamma$-semi closed set of X.

(ii) $\Rightarrow$ (iii) Suppose that A is a fuzzy $\gamma$-semi open set of X. Then $\gamma-\operatorname{scl}(\gamma-\operatorname{scl}(A))^{c}=\gamma$-scl $\quad\left(\gamma-\operatorname{sint}(A)^{c}\right)$. According to the assumption, $\gamma$-int $\left(A^{c}\right)$ is a fuzzy $\gamma$-semi closed set. So $\gamma$-scl $\left(\gamma\right.$-sint $\left.\left(A^{c}\right)\right)=\gamma$-sint $\left(A^{c}\right)=(\gamma$-scl $(\mathrm{A}))^{\mathrm{c}}$.

(iii) $\Rightarrow$ (iv) Let $A$ and $B$ be a fuzzy $\gamma$-semi open set of $X$ such that $B=(\gamma \text {-scl }(A))^{c}$. From the assumption we have, $\gamma-\operatorname{scl~B}=\gamma-\operatorname{scl}(\gamma-\operatorname{scl}(\mathrm{A}))^{\mathrm{c}}=(\gamma-\operatorname{scl}(\mathrm{A}))^{\mathrm{c}}$.

(iv) $\Rightarrow$ (i) Let A be a fuzzy $\gamma$-semi open set of $\mathrm{X}$. We put $\mathrm{B}=(\gamma \text {-scl }(\mathrm{A}))^{\mathrm{c}}$. From the assumption, we obtain that $\gamma$-scl $(\mathrm{B})=(\gamma-\operatorname{scl}(\mathrm{A}))^{\mathrm{c}}$,

so $(\gamma \text {-scl }(\mathrm{B}))^{\mathrm{c}}=\gamma$-scl(A). Hence $\gamma$-sint $\left(\mathrm{B}^{\mathrm{c}}\right)=\gamma$-scl(A). Thus $\gamma$-scl(A) is fuzzy $\gamma$-semi open set of X.

Definition 6.11: A fuzzy set A of fuzzy topological space $(X, \tau)$ is said to fuzzy $\gamma$-t-set if $\quad$ int $(A)=\operatorname{int}(\gamma$ $\operatorname{cl}(\mathrm{A}))$.

Theorem 6.12: $\operatorname{Let}(X, \tau)$ be a fuzzy topological space. Then a fuzzy subset A is fuzzy $\gamma$-t-set if and only if A is fuzzy $\gamma$-semi closed.

Proof:

Let $\mathrm{A}$ be a fuzzy $\gamma$-t-set. Then by using Definition 6.10, int $(\mathrm{A})=\operatorname{int}(\gamma-\operatorname{cl}(\mathrm{A}))$. Therefore $\operatorname{int}(\gamma-\operatorname{cl}(\mathrm{A}))=$ $\operatorname{Int}(\mathrm{A}) \leq \mathrm{A}$. Hence A is fuzzy $\gamma$-semi closed. Conversely, A is fuzzy $\gamma$-semi closed. Then by using Definition $2.1, \operatorname{int}(\gamma-\operatorname{cl}(\mathrm{A})) \leq \operatorname{int}(\mathrm{A})$. Also $\mathrm{A} \leq \gamma$-cl(A). This implies that int $\mathrm{A} \leq \operatorname{int}(\gamma-\operatorname{cl}(\mathrm{A}))$. Hence int $(\mathrm{A})=\operatorname{int}(\gamma-\mathrm{cl}(\mathrm{A})$. Thus A is fuzzy $\gamma$-t-set.

Theorem 6.13: Let $(\mathrm{X}, \tau)$ be an fuzzy topological space. If A is fuzzy $\gamma$-closed, then it is fuzzy $\gamma$-t-set.

Proof:

Let A be fuzzy $\gamma$-closed. Then by Proposition $2.10, \mathrm{~A}=\gamma$-cl(A) and

$\operatorname{int}(\mathrm{A})=\operatorname{int}(\gamma-\mathrm{cl}(\mathrm{A}))$.

Therefore A is fuzzy $\gamma$-t-set.

Theorem 6.14: Let $(X, \tau)$ be an fuzzy topological space. Then the intersection of any two fuzzy $\gamma$-t-set is fuzzy $\gamma$-t-set.

Proof:

Let $A$ and $B$ be fuzzy $\gamma$-t-set. Then by Definition 6.10, $\operatorname{int}(A)=\operatorname{int}(\gamma-\operatorname{cl}(A))$ and $\operatorname{int}(B)=\operatorname{int}(\gamma-$ $\operatorname{cl}(\mathrm{B}))$. Therefore $\operatorname{int}(\mathrm{A}) \wedge \operatorname{int}(\mathrm{B})=\operatorname{int}(\gamma-\mathrm{cl}(\mathrm{A})) \wedge \operatorname{int}(\gamma-\mathrm{cl}(\mathrm{B}))=\operatorname{int}(\gamma-\mathrm{cl}(\mathrm{A}) \wedge \gamma-\mathrm{cl}(\mathrm{B}))$. By Remark 2.6, $\operatorname{int}(\mathrm{A} \wedge \mathrm{B})=$ $\operatorname{int}(\gamma-\mathrm{cl}(\mathrm{A} \wedge \mathrm{B}))$.

The following example shows that union of two fuzzy $\gamma$-t-set need not be fuzzy $\gamma$-t-set.

Example 6.15: Let $X=\{a, b\}$ and $\tau=\left\{0,1,\left\{a_{\cdot}, b_{.3}\right\},\left\{a_{.9}, b_{.7}\right\}\right\}$. Then $(X, \tau)$ is a fuzzy topological space. The family of all fuzzy closed sets of $\tau$ is $\tau^{c}=\left\{0,1,\left\{a_{.9}, b_{.7}\right\},\left\{a_{.1}, b_{.3}\right\}\right\}$. Consider $A=\left\{a_{.4}, b_{.7}\right\}$ and $B=\left\{a_{.8}, b_{.6}\right\}$. Then $\operatorname{int}(A)=\left\{a_{\cdot 1}, b_{\cdot 3}\right\}$ and $\operatorname{int}(B)=\left\{a_{\cdot 1}, b_{\cdot 3}\right\}$. It follows that int $(\gamma-\operatorname{cl}(A))=\left\{a_{\cdot 1}, b_{\cdot 3}\right\}$ and $\operatorname{int}(\gamma-c l(B))=\left\{a_{\cdot 1}, b_{\cdot 3}\right\}$. Therefore by Definition 6.10, $A$ and $B$ are fuzzy $\gamma$-t-set. Now $A \vee B=\left\{a_{.8}, b_{.7}\right\}$ and int $(A \vee B)=\left\{a_{.1}, b_{.3}\right\}$ but $\operatorname{int}(\gamma-\operatorname{cl}(A \vee B))=\left\{a .9, b_{.7}\right\}$. It shows that $A \vee B$ is not an fuzzy $\gamma$ - $t$-set.

\section{References}

[1] M.Athar and B.Ahmad, Fuzzy Boundary and Fuzzy Semiboundary, Advances in Fuzzy systems, vol. 2008, 586893, 9 pages

[2] K.K.Azad, On fuzzy semi-continuity, fuzzy almost continuity and fuzzy weakly continuity, J.Math.Anal.Appl. 82(1)(1981), 14-32

[3] Biljana Krsteska , Fuzzy Strongly preopen sets and fuzzy strongly precontinuity, Mat. Vesnik 50(1998),111-123.

[4] C.L.Chang, Fuzzy Topological Spaces, J.Math. Anal, Appl.24(1968), 182-190.

[5] Luay A.Al.Swidi, Amed S.A.Oon, Fuzzy $\gamma$-open sets and fuzzy $\gamma$-closed sets, Americal Journal of scientific research, 27(2011), 62-67.

[6] T.Noiri and O.R.Sayed, Fuzzy $\gamma$-open sets and fuzzy $\gamma$-continuity in fuzzitying topology, Sci. Math. Jpn. 55(2002).

[7] A.K. Katsaras and D.B. Liu, Fuzzy vector spaces and fuzzy topological vector spaces , .Math.Anal.Appl., vol. 58,no 1, pp. 135-146, 1977.

[8] L.A.Zadch, Fuzzy Sets, Information and control, vol.8, Pp 338-353, 1965. 